\title{
Emerging business models: Usage-driven acquisition
}

\author{
Nader Qaimari ${ }^{\mathrm{a}}$ and Bethany Dotson ${ }^{\mathrm{b}}$ \\ a Senior Vice President, Sales and Marketing, Gale, a part of Cengage Learning, 27500 Drake Road, \\ Farmington Hills, MI 48331, USA \\ ${ }^{\mathrm{b}}$ Market Development Manager, Gale, a part of Cengage Learning, 27500 Drake Road, Farmington \\ Hills, MI 48331, USA
}

Gale was founded in 1954 as a publishing company. Our flagship publication, the Encyclopedia of Associations, began a tradition of excellence in reference that has continued for more than sixty years. Gale's focus on innovation and quality has led to expanded and increasingly/digital products, including online research databases, digital archives, virtual education courses, and, of course, Library Journal's 2012 Best Overall Database, the Gale Virtual Reference Library (GVRL).

$G V R L$, Gale's proprietary eBook platform, features reference works from a variety of authoritative publishers, including more than one hundred partners. Content from these partners, including $\mathrm{ABC}$ CLIO, Sage, Elsevier, Wiley, Springer, Encyclopaedia Britannica and DK Publishing, makes up the majority of the more than 13,000 titles available on GVRL, all of which are sold through an unlimited, simultaneous access purchase (perpetual access) model.

In 2013, Gale developed an alternative purchase model, Usage-Driven Acquisition (UDA), in response to the challenges expressed by our customers. First, collection development is extremely timeconsuming. Librarians worry about spending large amounts of money on resources that may or may not be used; the risks can be large, and it is difficult to predict what titles or content will be most useful to students. Moreover, with all the options for purchase available in the marketplace - patron-driven acquisition (PDA), demand-driven acquisition (DDA), subject collections, a la carte title selection, single-user, multi-user - making a single simple purchase can be overwhelming.

While these existing models are targeted at simplifying the collection development process, none resolve the unique challenges presented by reference materials. "What I like about [Gale's UDA program] is that ... you're not automatically bumped into purchasing it if someone looked at it 12 times if it doesn't fit your curriculum”, says Robin Bernstein, Senior Director of Library Services at Bellevue University, as opposed to a patron-driven acquisition model (PDA), which does trigger purchase based on a set number of views. DDA, or demand-driven acquisition, features the same trigger model.

Instead, UDA offers a simple four-step process. First, libraries select an amount to deposit in their UDA account, with the caveat that increased levels of investment merit increased title bonuses. For example, for $\$ 20,000$ down, libraries will receive $\$ 26,000$ in deposited funds.

Second, libraries receive unlimited access to a collection of up to 2,000 reference titles for a full six months. This includes all titles from all Gale imprints: Gale, Lucent Books, Charles Scribner's Sons, UXL, St. James Press, MacMillan Reference USA, Schirmer Reference, Information Plus and Green- 


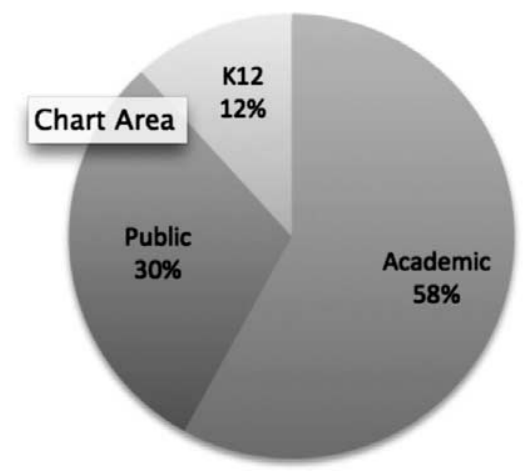

Fig. 1. Percentage of UDA sales by library type, November 2013-May 2014.

haven Press. We request that customers place a link to the collection on the library's website and/or load the provided MARC records.

Third, libraries get to use the new reference collection. At purchase, we work with customers to make suggestions on how they may choose to market these new resources. We provide usage-driving tools like widgets and curriculum alignment support, as well as instructions on incorporating content into LibGuides, to make sure that customers are able to get the most use possible of this collection.

Finally, at the end of the six-month access period, customers proceed to step four: own the collection. We provide a customized usage report that shows what titles in the UDA collection were used most. The library then owns, with perpetual, unlimited simultaneous access, the titles that were used most that are covered by the initial deposit. Libraries do have a seven-day grace period to swap out any titles that may represent an exception in usage. They can then make an additional deposit and start the program all over again!

The initial response to this program has been phenomenal. Approximately fifty libraries, mainly academic and public, signed on in the first month of the offer, and numbers continue to grow month after month. The average investment in UDA is $\$ 10,000$, with many over $\$ 40,000$, and the majority of customers represent non-previous purchasers.

Going forward, we have a number of enhancements under consideration. We're currently working to expand the UDA model to include content from partner publishers, including branching out from the main UDA collection to establish publisher-specific and subject-specific UDA collections. Based on our earlier success, we are identifying products which have potential to be sold under a UDA model: for example, Archives Unbound, Gale's special collections platform. Finally, we are working to create a UDA offering through the wholesaler partners.

The release in May 2014 of Gale's new InterLink functionality for all InfoTrac products increases both the feasibility and attraction of the UDA program for customers who have access to InfoTrac products, such as General OneFile or Academic OneFile. Figure 2 shows a screenshot of how InterLink adds to the user experience.

The overwhelmingly positive response to UDA gives credit to the continuing need of libraries to increase understanding of patron trends, needs, and patterns of use. It is our ongoing mission at Gale to provide the tools that libraries need to be successful in an increasingly competitive and dynamic industry. ${ }^{1}$

\footnotetext{
${ }^{1}$ This paper is based upon a presentation given at the 2014 NFAIS Annual Conference in Philadelphia, PA, USA on February 25, 2014. The slides can be accessed on the NFAIS Web site at http://www.nfais.org.
} 
Full Text:

Authors: Cory Sarks (corresponding author) [1,2]; Mingjie Jin (corresponding author) [1,2]; Trey K Sato [3]; Venkatesh Balan [1,2]; Bruce E Dale $[1,2]$

Background

Biofuels have recently gained momentum in academic research, government, and large companies [1, 2]. The benefits of biofuels have been widely accepted by society, although some controversy remains because of perceived conflicts with food production [3]. Nevertheless, biofuels represent a renewable option to replace a depleting oil supply and can help mitigate the climate change impacts of fossil fuel use [4]. Furthermore, a large-scale biofuel industry would improve energy security and strengthen the world economy.

Lignocellulosic biomass is a potential feedstock for low cost biofuel production [5]. The cost of lignocellulosic biomass is projected to be lower than prices for starch, which is currently used to produce bioethanol in the US [6,7]. Currently, agricultural residues such as corn stover (the leaves, husks, and stalks of corn plants) are usually left in fields [8]. There is also the potential to plant double crops and cover crops for added biomass productivity, improved soil chemistry, and fertilizer sequestration [9]. Additional biomass could be produced by cultivating dedicated energy crops on marginal lands unsuitable for food production [10].

Lignocellulosic biomass is highly recalcitrant and difficult to convert into monomeric sugars that can be fermented into biofuels by microorganisms [11]. Chemical and physical pretreatment processes are thus used to disrupt biomass allowing the structural carbohydrates to be more easily hydrolyzed to monomeric sugars by biomass degrading enzymes $[11,12]$. Thermochemical pretreatment processes generate degradation products that often are toxic to the microorganisms and $r$ Articles for Enzymes

$14,15]$. The high price of lignocellulosic enzymes and the long process times re Enzymes, Industrial (Biotechnology: Changing Life Thro... are two bottlenecks preventing economical production of lignocellulosic ethanol Enzymes: Biotechnological Applications (Encyclopedia o... Bioconversion with Integrated recycle Technology (RaBIT) process was develop, Enzymes: Biotechnological Applications
presentations we have referred to this process as BCRL SHF, BCRL SSCF, Fast $\subseteq$ Enzymes (Science of Everyday Things) Laboratory, SHF: separate hydrolysis and fermentation, SSCF: simultaneious se Euler-Chelpin, Hans Karl Auqust Simon von (Complete... The RaBIT process (Figure?1) reduces capital costs by shortening enzymatic hy Euler-Chelpin, Hans Karl Auqust Simon von (Encyclope... potentially reduce enzyme usage up to $50 \%$. This is accomplished by recycling 1 Fungal Fermentation: Industrial (Encyclopedia of Life S... enzymes into the next cycle of enzymatic hydrolysis. This will lead to a buildup Genomics, Environmental (Encyclopedia of Environment... portion of the unhydrolyzed solids will need to be removed periodically. Future I Bacterial Physiology and Metabolism (McGraw-Hill Ency...

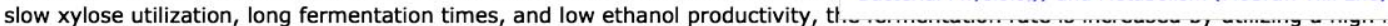
cell densitv (annroximatelv $10 ? 0 / 1$ drv cell weiaht [DCW1) counled with cell recvclina into the next fermentation stace. As a result.

Fig. 2. Screenshot of InterLink functionality as displayed on Academic OneFile, May 27, 2014. (Colors are visible in the online version of the article; http://dx.doi.org/10.3233/ISU-140728.)

\section{About the author}

Nader Qaimari has worked in the library industry for fifteen years. Starting as a print editor and then managing many of Gale's product lines, he currently serves as Cengage Learning's Senior Vice President of Sales and Marketing, focusing mainly on the library markets. Nader has held positions in product management, strategy, and has also managed a number of major product launches. Nader has a BA in English Literature from Kenyon College and an MBA from the University of Michigan. 


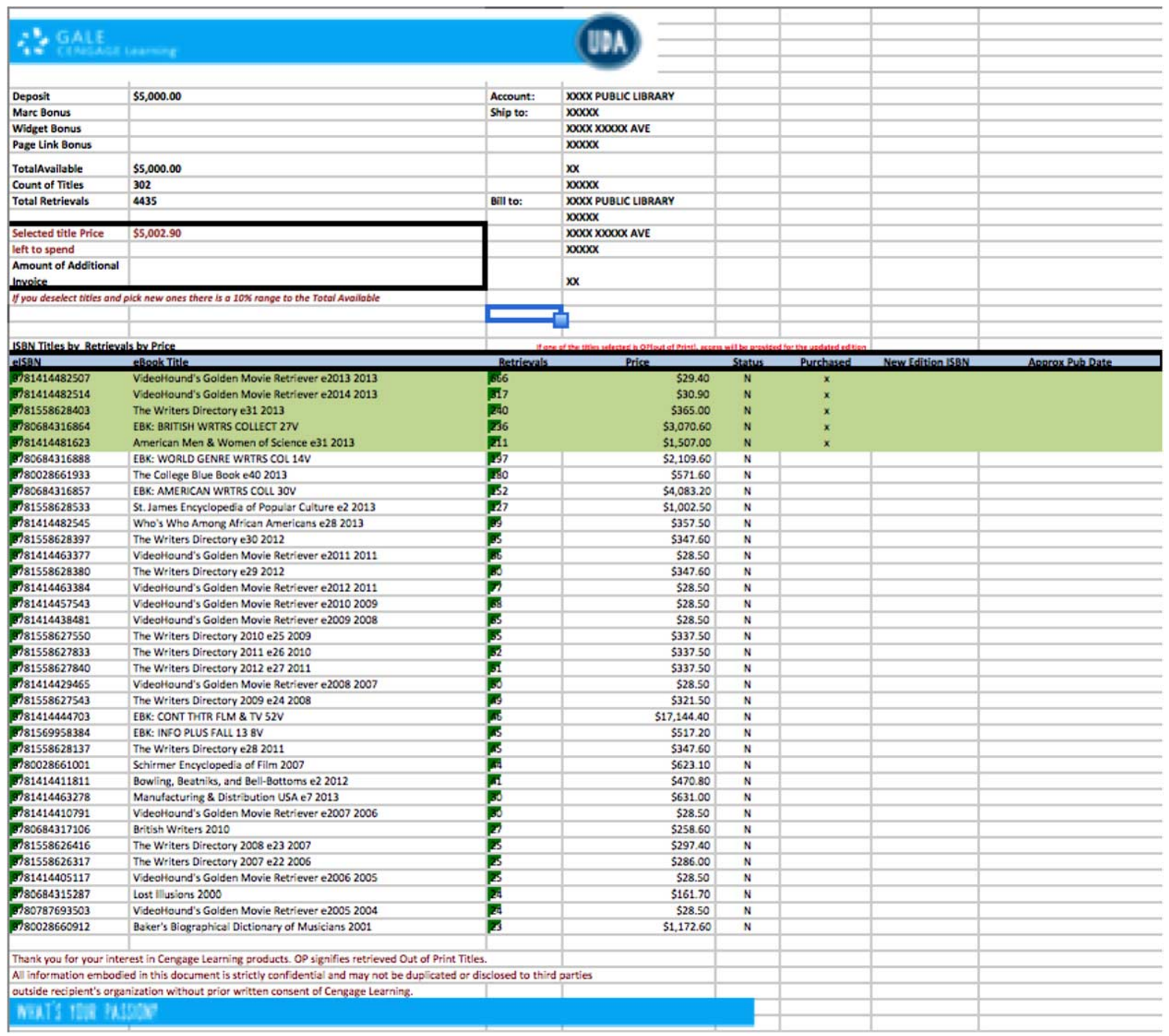

Fig. 3. Sample UDA end-of-term report. (Colors are visible in the online version of the article; http://dx.doi.org/10.3233/ ISU-140728.) 